\title{
DESIGNING THE VALUE PROPOSITION OF SYSTEMIC EHEALTH INNOVATION ISEREADOM CASE STUDY
}

\author{
Angela Martin ${ }^{1}$, Véronique Chirie ${ }^{2}$ and Emmanuelle Chifflot ${ }^{3}$ \\ ${ }^{1}$ ALTRAN frog Design, 96 Avenue Charles de Gaulle, 92200 Neuilly-sur-Seine, France \\ ${ }^{2}$ TASDA, 163 Cours Berriat 38000 Grenoble, France \\ ${ }^{3}$ Département de l'Isère, 15 av du Doyen Louis Weil, 38000 Grenoble, France
}

\begin{abstract}
The goal of this paper is to provide an assessment tool of the acceptability and feasibility of an eHealth ecosystem innovation and how to deploy it on the field. The Value Proposition Canvas is applied to IsereADOM case study as a "score-board" to track if/ and how the innovation project actually eases pains and creates gains when testing it with customers. Beyond the interest of making readable and understandable the impact of such a complex project, the focus of this work is on the integration of the project value proposition at the national, regional, local level to overcome barriers but also pull out the best levers of the ecosystem.
\end{abstract}

\section{KEYWORDS}

ICT, Evaluation, Innovation, Value Proposition Analysis, Territorial Cooperation, eHealth, Well Aging

\section{INTRODUCTION}

While eHealth innovation projects have a great potential to address healthcare disparities, the great majority are not deployed beyond the pilot stage. Moreover, the organization of the health industry is unique. Stakeholders are particularly dependent on each other and their multiplicity enhances the complexity of business models. We have already proved in our previous work that, by taking a complex system modelling approach, we can provide a tool, for both entrepreneurs and investors, that offers a comprehensive view of value streams by the comparison of different business models based on the economic shared value creation during the go to market process (Martin et al., 2018).

In the present paper, we extend to non-economic value from Organisational Complex System Modelling framework (OCSM): quality of care, social, medical (Jean et al., 2016; Martin et al., 2019). In fact, for Porter (2011), generating social and medical value is a competitive advantage.

The goal of this paper is to provide a design thinking framework of the central component of a business model: the Value Proposition (Osterwalder et al., 2010; 2015). The focus here is to deep dive into the way organizations function and create value by using IsereADOM case study. The paper is organized as follows: in the next section, a literature review examines business model design and challenges and the methodology. The case study data and methodology (Value Proposition Canvas and the impact of the case study integration into its ecosystem) are described and discussed in the third section. Finally, a conclusion ends this paper.

\section{THEORETICAL BACKGROUND}

The field of business models has developed dramatically over the last ten years both in academia and in business and therefore we intend to shed some light on its central element i.e. the Value Proposition. According to the literature review, business models are classified into four categories: value proposition, value network, value finance and value architecture (Zott et al., 2011). 
Among the frameworks provided, the Value Proposition Canvas introduced by Osterwalder and Pigneur (2014) is one of the first to create a tool that specifically helps entrepreneurs to design the pivotal element of their business models. It gives a simple and accessible way of examining whether the value propositions of a company's business model correlates with the actual needs of the customers it wishes to serve (Osterwalder et al., 2015). Whereas the Business Model Canvas (Osterwalder and Pigneur, 2010) focused on how to create value for businesses, the Value Proposition Canvas focuses on how to create value to customers. By combining qualitative research and the impact measurement of the innovation on the ecosystem stakeholders, we design and test value propositions in an iterative search for what stakeholders want.

\section{METHODOLOGY APPLIED TO THE CASE STUDY}

By using a Value Proposition Canvas we focus on whether the innovation answers real customer pain points to ensure its adoption before the scaling up. In addition, the circumscription of the project value proposition at the national, regional, local level is necessary to overcome barriers but also pull out the best levers of the ecosystem.

\subsection{Project IsereADOM}

IsereADOM is a French eHealth demonstrator of efficiency of a set of services relating to information, support and care of frail or dependent people living at home. The project goal is to create more fluidity and decompartmentalising for home support. It is conducted by the Isère County council in consortium with financial partners (CARSAT, ARS AURA, AG2R LA MONDIALE, APICILE, CDC, EUROPE, REGION ARA), the assistant project owner (TASDA), and the industrial consortium gathered Altran, IMA, ORANGE (and their subcontractors). The project has been conducted with the support from different stakeholders involved in home healthcare, either with national and remote offers (such as medical monitoring or remote assistance), or with local offers (such as care givers, nurses).

Carried out over 5 years (2.5 years of development, 2 years of field trials, 0.5 year of evaluation), the project involved nearly 150 actors, from more than 20 different companies. All IsereADOM components have been evaluated. 13 thematic reports were produced, about public services, personalized supports for frail people, project management, economic balance, IT solutions' diagnosis, etc. The assessment results are based on online surveys, focus groups, individual and telephone interviews, statistics analyses on the use of digital tools, medico-economic analyses, feedback sharing from the actors involved. The web portal reached more than 15,000 visitors, mobilizing more than 1,000 service providers for the directory of local services. Personalized support was carried out with 200 seniors, with the mobilization of around 100 professionals.

Finally, IsereADOM consists in:

- A development toolbox, which have been applied to further advantage in the form of computer modules (such as a web directory of local services, a digital link notebook, etc.), formalized business processes (such as "processing requests arriving at the call centre", "carry out sentinel monitoring", etc.), communication and training tools.

- Acknowledged expertise in setting up a complex organisational innovation, change management support, integration into existing organizations and tools, management of arbitrations with locally elected bodies. The "engineering" component is an essential point of the project, essential to make available to other territories in case of future deployment.

IsereADOM assessment data gathered is used for designing the Value Proposition Canvas (here after) and for measuring the impact of the project at the local, regional and National level (see 3.3). 


\subsection{Value Proposition Canvas}

The Value Proposition Canvas (VPC) describes the features of a specific value proposition in the business model in a more structured and detailed approach (Osterwalder et al., 2014). The VPC (figure 1) breaks the value proposition down into products \& services, pain relievers and gain creators (on the left side). On the right side, the customer (segment) profile where the customer understanding is clarified: the jobs the customers are trying to get done in their lives and their work, the pains describing bad outcomes, risks and obstacles related to customer jobs and finally the gains, the outcomes they want to achieve or the concrete benefits they are seeking. The goal is to achieve a fit between the two sides of the model. Three type of fit are possible depending on the maturity of the project:

1) Problem-solution fit: evidence that the customers care about the jobs, pains and gains IsereADOM intends to address with the value proposition.

2) Product \& services-market fit evidence that customers want the value proposition of IsereADOM.

3) Business model-fit evidence that the business model for IsereADOM value proposition is scalable and profitable.

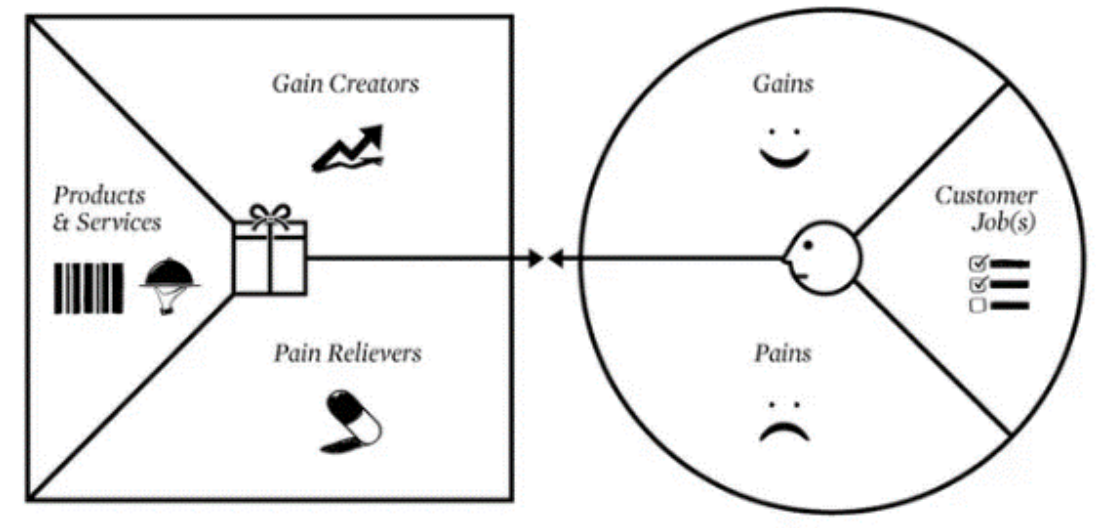

Figure 1. Value Proposition Canvas
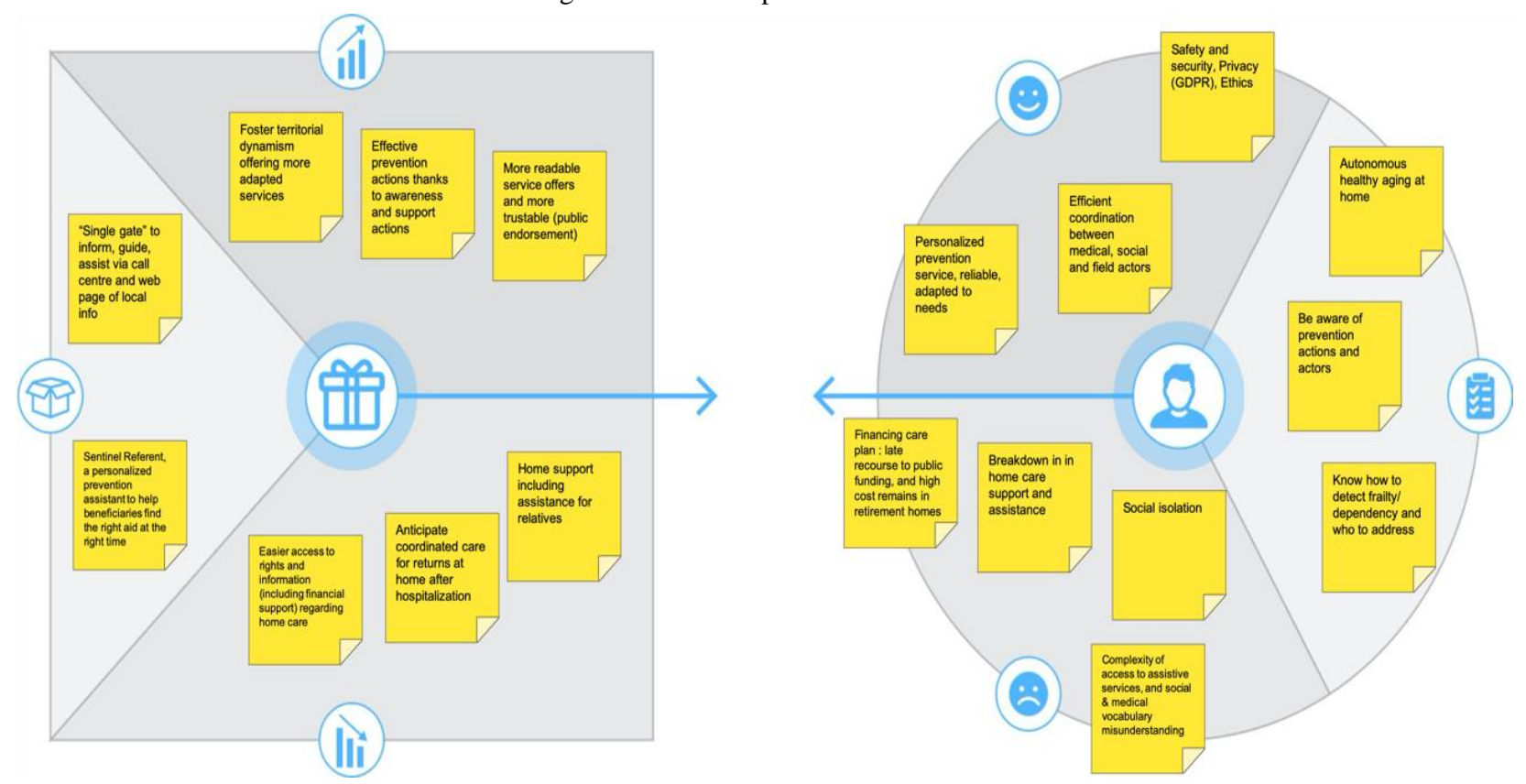

Figure 2. IsereADOM Value Proposition Canvas for the Beneficiary 
Based on IsereADOM assessment data gathered, we bring evidence that IsereADOM creates value for the customers by investigating the product \& services market fit. The fit is achieved when IsereADOM services produce pain relievers and gain creators that match one or more of the jobs, pains and gains that are important for the two segments identified as IsereADOM customers are: the beneficiary of the services i.e. the elderly living at home (figure 2) and their designated caregiver called the Sentinel Referent (see figure 3 below).
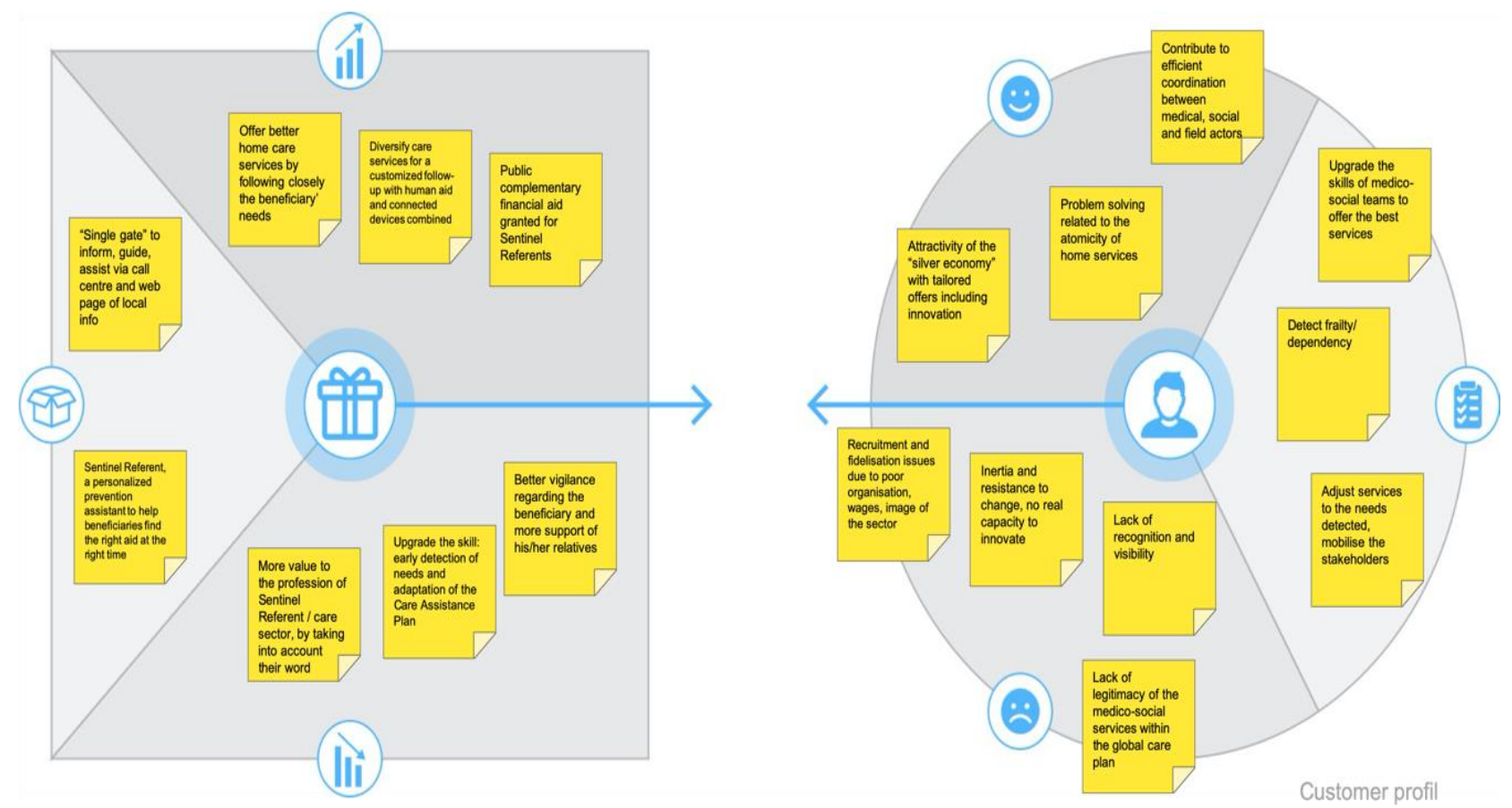

Figure 3. IsereADOM Value Proposition Canvas for Sentinel Referent

The beneficiary customer profile is described on the right side of figure 2 . Their jobs to be done are: autonomous healthy aging at home and so they need to increase their awareness regarding prevention actions by detecting frailty/ dependency and the local stakeholders (actors) to address. The pains are: social isolation, the complexity of access to assistive services, the misunderstanding of social and medical vocabulary that may lead to a breakdown in home care support and assistance and the risk of premature exhaustion of the family caregiver. A particular highlight is on the financing of the dependency by a late demand of public funding, and a very high "out of pocket" for people living in retirement homes. The gains that the beneficiary would like to obtain are: personalized prevention services that are not only reliable but also adapted to their needs offering more comfort and social bonds; services compliant to safety, security, privacy and ethics. An efficient coordination between medical, social and field actors may avoid breakdowns and social isolation.

The sentinel referent customer profile is described on the right side of figure 3 . The jobs they are trying to perform and complete are: detect the frailty/ dependency early signs of the beneficiary by adjusting services to the needs detected, mobilising the "right" stakeholders, upgrade the quality of their services by improving the skills of medico-social teams on the field. What annoys the sentinel referents or simply prevent them to perform their job is: the lack of recognition and visibility accompanied by the lack of legitimacy of the medico-social services within the global care plan, the inertia and resistance to change with no real capacity to innovate, recruitment and fidelisation issues due to the poor organisation, low wages and bad image of the caregiver job. The sentinel referents expect to contribute to problem solving related to the atomicity of home services stakeholders and to a more efficient coordination between medical, social and field actors. Furthermore, they desire a better attractivity of the "silver economy" (destined to seniors) with tailored innovation offers.

The use of the customer profiles helped IsereADOM visualize what matters to the beneficiary and sentinel referent. As a "score-board" it helps to give a global vision of the needs and responses produced, which are multiple, complementary, different. 
On the left side of the VPC (figure 2 and 3), the services offered by IsereADOM are described:

1) A "single gate" access to general information and orientation on local services (personal services, housing, transportation, leisure, etc.) and local prevention activities (health and well-being); a call center and a website (with a database) gathering information on local resources and facilitating everyone's access to this information; a personalized support component for people living at home with decreasing independence.

2) Thanks to the designation of a Sentinel Referent (SR) using a digital link notebook, the care giver identifies the senior status change and calls on a doctor or the Department referent to adapt the care/aid plan. The "sentinel referent process" involves services like: teleconsultation, tele-assistance, telephone coaching combined with human intervention. The goal is to detect frailty/ dependency in order to search for the right assistance at the right time.

The value proposition of IsereADOM services is what figure 2 and 3 have in common. What differs is the benefits customers can expect from IsereADOM because the pains they struggle with and the gains they try to get depend on the jobs to be done in their lives (beneficiaries) or their work (sentinel referents). So two main benefits or gain creators arise from using IsereADOM services. From the beneficiary's point of view, more prevention (less avoidable hospitalization, complexity, ...) to support autonomy, thanks to a good shared knowledge of the beneficiary and his/her situation at home. This benefit must result in both a better quality of life but also more efficient means of care. The VPC (figure 2) shows how IsereADOM brings a global approach of the "well aging" with home support, thanks to information, coordination, access to the adapted local services or local prevention action, within the GDPR framework. From the SR point of view, a modernization of the medico-social sector, with real recognition of the SR added value (the detailed knowledge of the beneficiary), including in coordination and the promotion of his/her profession. This leads to better working conditions, more ease of recruitment and better quality service and so one. The VPC in figure 3 shows how IsereADOM brings the opportunity to innovation, sustainability, change for more efficient, thanks to a systemic approach with tools (ICT solutions), process and a foundation of public funding.

Hence, the answer provided by IsereADOM to support autonomous healthy aging at home creates some essential gains for its customers. It also relieves real customers pains. For the beneficiary it offers easier access financial support rights and information regarding home care; coordinated care anticipated in case of returns at home after hospitalization, home support including assistance for the family care giver. For the sentinel referent, IsereADOM brings more value to the profession of the care giver, by taking into account their word, upgrading their skills in early detection of needs in the adjustment of the Care Assistance Plan for a better vigilance regarding the beneficiary and offering more support to their relatives.

\subsection{IsereADOM Impact}

The value proposition canvas is qualitative and focused on one type of customer. If they are explicit and representative of a shared customer understanding, they must nevertheless be translated into quantifiable indicators to measure real benefits.

The impact matrix makes it possible to translate the values proposition canvas into indicators giving a holistic view. It also restores a global vision of the project by specifying the stakeholders and the coherence and complementarity of the benefits for each of them. The impact matrix thus highlights the systemic approach and the circumscription of the Value Proposition of IsereADOM into the local, regional, national ecosystem.

To go further we need to apply a systemic design approach (Barbero, 2016) that integrates system thinking and human centered design) to study the externalities both positive and negative on the systems (political, economic, environmental, social, behavioral) at short, mid and long-term to be able to conceive the strategy of the scaling up of IsereADOM. 
Table 1. IsereADOM Impact on Stakeholders

\begin{tabular}{|c|c|c|c|c|c|c|c|c|c|c|c|c|}
\hline & & & & \multicolumn{9}{|c|}{ STAKEHOLDERS } \\
\hline & & & & $\begin{array}{l}\text { Benefi- } \\
\text { ciary }\end{array}$ & $\begin{array}{l}\text { Rela- } \\
\text { tives }\end{array}$ & $\begin{array}{l}\text { Care } \\
\text { giver } \\
(\mathrm{SR})\end{array}$ & $\begin{array}{l}\text { County } \\
\text { council }\end{array}$ & $\begin{array}{l}\text { Pension } \\
\text { Fund }\end{array}$ & Hospitals & $\begin{array}{l}\text { Local } \\
\text { authority }\end{array}$ & $\begin{array}{l}\text { National } \\
\text { Health } \\
\text { fund }\end{array}$ & $\begin{array}{l}\text { Industry } \\
\text { start up }\end{array}$ \\
\hline \multirow{4}{*}{\multicolumn{2}{|c|}{ 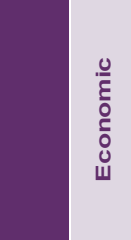 }} & Ind 1 & Better efficiency of health \& care spending & $x$ & $x$ & $x$ & $x$ & $x$ & $x$ & & $x$ & \\
\hline & & Ind 2 & Improved local and national policy coordination & & & $x$ & $x$ & $x$ & & $x$ & $x$ & \\
\hline & & $\ln 3$ & Increased no of recruitments of care givers & & & $x$ & $x$ & & & $x$ & & \\
\hline & & $\operatorname{lnd} 4$ & Connected device market development & $x$ & $x$ & $x$ & & & & & & $x$ \\
\hline \multirow{4}{*}{\multicolumn{2}{|c|}{$\begin{array}{ll}0 & \bar{\sigma} \\
0 & 0 \\
0 & \infty\end{array}$}} & $\operatorname{lnd} 5$ & Better quality of life & $\mathrm{x}$ & $x$ & & & & & & & \\
\hline & & $\ln 6$ & Better access to healthy aging at home info & $x$ & $x$ & $x$ & $x$ & $x$ & & & & \\
\hline & & $\operatorname{lnd} 7$ & Modernization of the medico social sector & & & $x$ & $x$ & & & & & \\
\hline & & $\operatorname{lnd} 8$ & $\begin{array}{l}\text { Promotion of local services \& activities / territorial } \\
\text { "anchoring" and development }\end{array}$ & $x$ & $x$ & & $x$ & & & $x$ & & \\
\hline & \multirow{6}{*}{$\begin{array}{l}\frac{0}{\pi} \\
0 \\
\frac{0}{0} \\
\frac{2}{ \pm} \\
\frac{\pi}{3}\end{array}$} & $\operatorname{lnd} 9$ & Higher efficiency of care givers & $\mathrm{x}$ & $x$ & $\mathrm{x}$ & $x$ & & & & & \\
\hline & & Ind 10 & $\begin{array}{l}\text { Continous integrated care vigilance by human \& } \\
\text { technological inputs }\end{array}$ & & & $x$ & $x$ & $x$ & $x$ & & $x$ & $x$ \\
\hline & & Ind 11 & $\begin{array}{l}\text { Better awareness of beneficiary needs \& frailty } \\
\text { shared information }\end{array}$ & $x$ & $x$ & $\mathrm{x}$ & & & $x$ & & & \\
\hline & & Ind 12 & $\begin{array}{l}\text { Improving ICT interfaces for health \& care } \\
\text { software }\end{array}$ & $x$ & $x$ & $x$ & & & & & & $x$ \\
\hline & & Ind 13 & Local coordination embedding & & & $x$ & & & $x$ & $x$ & & \\
\hline & & Ind 14 & $\begin{array}{l}\text { Responsiveness of the adaptation of health \& care } \\
\text { plans }\end{array}$ & $x$ & $x$ & $x$ & $x$ & & $x$ & $x$ & $x$ & \\
\hline
\end{tabular}

\section{CONCLUSION}

Two main sets of interest arise from the work of formalizing the value proposition map, in addition to its strategic support. Firstly, it is necessary to structure the values proposition in a clear manner for a systemic project with so many components and geographical levels like IsereADOM. Replacing words with meaningful and instructive pictures give a better readability of the VPC thanks to the mapping of the value created for its customers. This readability is necessary for all the actors of the project but also the stakeholders in connection with the subjects that the project addresses. Secondly, innovation projects for frail people living at home must consider not only their acceptability as beneficiary but also the acceptability of the referent sentinel (private healthcare professionals or care givers). Furthermore, the VPC of IsereADOM provides an interesting synthesis of the key points of home care for elderly people in terms of challenges, expectations, levers.

Strategy is about creating actual value so this work is a contribution to entrepreneurs and innovation project managers who need to renew their business models by calling the interest and the feasibility of the innovation into the ecosystem into question.

\section{REFERENCES}

Barbero, S., 2016. Opportunities and challenges in teaching Systemic Design. The evolution of the Open Systems master courses at Politecnico di Torino. In Proceedings of the 6th International Forum of Design as a Process, Universitat Politècnica de València, Valencia, pp. 57-66.

Gorskia, I., Brama, J. T., Sutermastera, S., Eckmana, M. and Mehtab K. Value propositions of mHealth projects, In Journal of Medical Engineering \& Technology, august 2016. 
Jean, C., Duong, T., Cardinal, J., Jankovic, M., Bocquet, J., and Espinoza, P., 2016. Sharing economic value between the stakeholders of a telehealth project: methodological issues?, In Eur. Res. Telemed., vol. 5, pp. 37-44.

Martin, A., Canu, C., Jean C., Breda, G., 2018. E-health deployment business model tele-expertise case study, In MCCSIS e-Health 2018 Proc, Outstanding Paper Award 2018.

Martin, A., Cosandier- Rimele, D., Canu C., Breda G., 2019. New system economic evaluation of ehealth innovation, In MCCSIS e-Health 2019 Proc, Best Paper Award 2019.

Osterwalder, A. and Pigneur, Y., 2010. Business Model Generation. John Wiley \& Sons.

Osterwalder, A., Pigneur Y., Bernarda G., Smith A. and Papadakos T., 2015. Value Proposition Design How to create products and services customers want, In Journal of Business Models, vol. 3, no. 1, pp. 81-89.

Porter, M., and Kramer, M., 2011. Creating shared value - How to reinvent capitalism and unleash a wave of innovation and growth, In Harvard Business Revue., vol. 39, pp. 62-77.

Zott, C., Amit, R. and Massa, L., 2011. The Business Model: Recent Developments and Future Research, In J. Manage., vol. 37, no. 4, pp. 1019-1042. 